\title{
Distribution of Socio-Economic Factors with Malaria Occurrence at Federal Capital Territory Abuja, Nigeria: A Retrospective Hospital Based Study
}

\author{
Article by Ibrahim S. A ${ }^{1}$, Ukaga C.N ${ }^{2}$ \\ ${ }^{1}$ Department of Health Planning, Research and Statistics, FCT HHSS Abuja, Nigeria \\ ${ }^{2}$ Department of Animal \& Environmental Biology Faculty of Science Imo State University, \\ Nigeria \\ E-mail:ohikwo2003@yahoo.com
}

\begin{abstract}
Malaria remains one of the number one killer diseases in sub-Saharan Africa especially in Nigeria. In the Federal Capital Territory (FCT), Abuja, malaria is the leading cause of morbidity. A retrospective hospital based study on the distribution of socio economic factors with malaria occurrence at FCT Abuja Nigeria was carried out using a five years (2012-2016) hospital records from Wuse District Hospital Abuja. Sampling Technique includes all the patients' records that were diagnosed of acute malaria confirmed by Giemsa stained thick and thin peripheral blood films prior to treatment at the General Out Patient and those on admission at Wuse District Hospital Abuja. Data was entered and analyzed using IBM, SPSS Chicago version 25. Appropriate tables, graphs and percentages were displayed. A chi square test was performed to determine the level of significance using $95 \%$ confidence interval and $p$-value. The findings revealed that a total of 22,934 patients were diagnosed with acute malaria based on hospital records between 2012 and 2016 in Wuse District Hospital Abuja. From the analysis, the Non Formal Educational accounted for 57.4\% of the total number of patients diagnosed.Those who are unemployed accounted for $77.3 \%$ and those living in the rural area accounted for $55.7 \%$ of the cases. The study concluded that, The level of educational status, occupational status and residence of patients plays significant roles in the occurrence of malaria infection.
\end{abstract}

Keywords: Socio Economic, Malaria, Distribution, Factors, occurrence.

\section{Introduction}

Malaria remains one of the number one killer diseases in sub-Saharan Africa especially in Nigeria. Africa still bears over 80 percent of the global malaria burden, and Nigeria accounts for about 29 percent of this burden (WHO Malaria Report 2014). This diminutive monster has taken its greatest toll on children under age 5 and pregnant women, although it is preventable, treatable, and curable.

In Nigeria, malaria is responsible for approximately 60 percent of outpatient visits and 30 percent of admissions (FMOH 2014 b). It also contributes up to 11 percent of maternal mortality, 25 percent of infant mortality, and 30 percent of under-5 mortality (FMOH 2014b). It is estimated that about 110 million clinically diagnosed cases of malaria and nearly 300,000 malaria-related childhood deaths occur each year in Nigeria. The disease overburdens the already-weakened health system and exerts a severe social and economic burden on the nation, retarding the gross domestic product (GDP) by 40 percent annually and costing approximately 480 billion naira in out-of pocket treatments, prevention costs, and loss of man hours (WHO Malaria Report 2014).

Other recent study indicates that, 85 percent of Nigerians live in areas of mesoendemic transmission, and only 15 percent live under conditions of hyperholoendemic transmission. There are conditions of hypo endemic transmission in areas of the FCT, Adamawa, and Borno (Snow et al 2013). Also, a malaria transmission intensity mapping study using several data sources and geostatistical modeling techniques has shown changes in parasite risk patterns during the past decade, with parasite risks falling in 19 of the 36 states and the FCT. The study showed a 50 percent reduction in malaria morbidity in these areas (Snow et al. 2013). 
Malaria is caused by plasmodium species and the most prevalent species of malaria parasites in Nigeria is Plasmodium falciparum (greater than 95 percent). It is responsible for the most severe forms of the disease. The other types found in the country include: $P$. ovale and $P$. malariae, which play a minor role. $P$. malaria is commonly isolated from children with mixed infections (WHO Malaria report 2012)

Substantial Malaria control investment in the FCT Abuja has been made during the last decade following the implementation of the FCT Health Sector Strategic Plan of 2010- 2015. The FCT Malaria Control Strategy as part of FCT Strategic Health Development Plan of 2010-2015 was conceived with the vision that, malaria will no longer be a major public health problem in the FCT Abuja as illness and death from malaria will significantly be reduced.

The Global Funds supported FCT with the distribution of six (6) millions nets during mass campaign from 2013 to 2015. Non-Governmental Organizations also distributed LLITNs in some communities of the FCT. The Save One Million Live (SOML) programme funded by World Bank equally distributed a total of 55,000 Nets targeting under 5yrs in the 31 political wards (50\%) of the Federal Capital Territory Abuja (FCT HHSS 2015 report). This was done between 2015 and $3^{\text {rd }}$ quarter of 2017. As at the last quarter of 2017, the support for the provision of the Insecticide Treated Net stopped due to lack funds from donor organizations (FCT HHSS 2017 report) The Global funds and the FCT MDGs office also supported the provision of the ACT drugs which were distributed to the health facilities between 20102015.

Despite these investments, malaria still remains the leading cause of morbidity, followed by Diarrhea, Accident, Pneumonia, Measles and Malnutrition. In the FCT, Abuja, Nigeria, malaria accounted for about $70 \%$ of hospital attendance in the GOPD and 50\% of medical admissions (FCT HHSS 2015b). Malaria prevalence rate in the FCT stood at $43 \%$ based on the 2015 National Malaria Indicator Survey report. Other key findings and challenges on FCT malaria control strategies are presented in the following thematic areas:

\section{a. Integrated vector management situation}

- Non-attainment of universal coverage of Insecticides Treated Nets with \% Distribution of mosquito nets of $49 \%$ compared to Ekiti state that has distribution of $97 \%$ and national target of $100 \%$ (NMIS 2015)

- The rate of utilization of LLINs was as follows: $2014-16.5 \%, 2015-24.5 \%, 2016-28.5 \%$ based on a smart survey done in the FCT. But the National Malaria Indicator reported the rate of utilization to be $17 \%$ in 2015 . This was lower than the national average of $37 \%$.

- Ownership of ITN for FCT $45 \%$ as against 69\% national average (NMIS 2015)

- There were no proper baseline entomological indices in the FCT prior to LLITNs implementation.

- Indoor and Outdoor Residual Spray is still rudimentary in the FCT Abuja.

- Absence of Malaria Technical Working Group in the FCT Abuja

- There was absence of Integrated Community Case Management in the FCT malaria control programme.

\section{b. Diagnosis and treatment situation}

- The Federal Capital Territory (FCT) has 858 rural communities across the six area councils. A total of 633 (74\%) of these communities has no primary healthcare clinics. Of which 336 of these communities belongs to the lowest poor with poverty index of $<1 \mathrm{USD} /$ day. A total of $76 \%$ depend mainly on farming for their means of livelihood. Only $2 \%$ of the residents earn above 140USD per annum (FCT baseline 2009)

- WHO estimated that adequately serving the population of FCT residence in 2009 would require 434 Primary Health Clinics, but only 179 existed. Out of this, only 17\% were fully functioning and many of which were operating at sub-optimal levels or located long distances from rural populations (FCT baseline 2009). All these lead to Inequity in access to appropriate treatment for malaria case for those in the rural areas. 


\section{c. Malaria in pregnancy}

- Intermittent Preventive Treatment (IPT) is one of the preventive strategies of malaria in pregnant women. However, the uptake is still low in FCT with IPT1 at 19.2\% and IPT2 at 14.9\%. However, there were Persistent reports of Sulfadoxine-Pyrimethamine stock out due to lack of sustained funding.

- Based on the situational analysis above, this retrospective study examined how socio economic factors affect malarial control in the FCT Abuja. Indeed studying malaria trends is considered as one of the most important aspect of employing effective control strategies in Malaria prone settings.

\section{Aim of the study}

To show the distribution of socio- economic factors with malaria occurrence at FCT Abuja Nigeria

\section{Materials and methods}

\section{Study area}

FCT is located in the North Central geopolitical zone of the country. The territory hosts the capital city of Nigeria, Abuja. It is bounded by Niger State and Kaduna States in the north, Nasarawa State in the east, Nasarawa and Kogi States in the south and Niger State in the west. It has a land area of 8,000 square kilometres. It falls within the Savannah zone vegetation of the West African sub-region. However, patches of rain forest occur in the Gwagwa plains that form one of the surviving northernmost occurrences of the mature forest vegetation in Nigeria. According to 2006 census, the population was $1,406,239$. However, the projected population for 2017 is $3,740,080$. The rapid rise in the population is as a result of growth rate of $9.3 \%$, a level considerably above the national level of $3.2 \%$.

The study was conducted in Wuse District Hospital Abuja Nigeria in the Abuja Municipal Area Council of the Territory. The hospital was chosen because; it is the most accessible public hospital with the highest number of bed space and high patient load compared to other public hospitals.
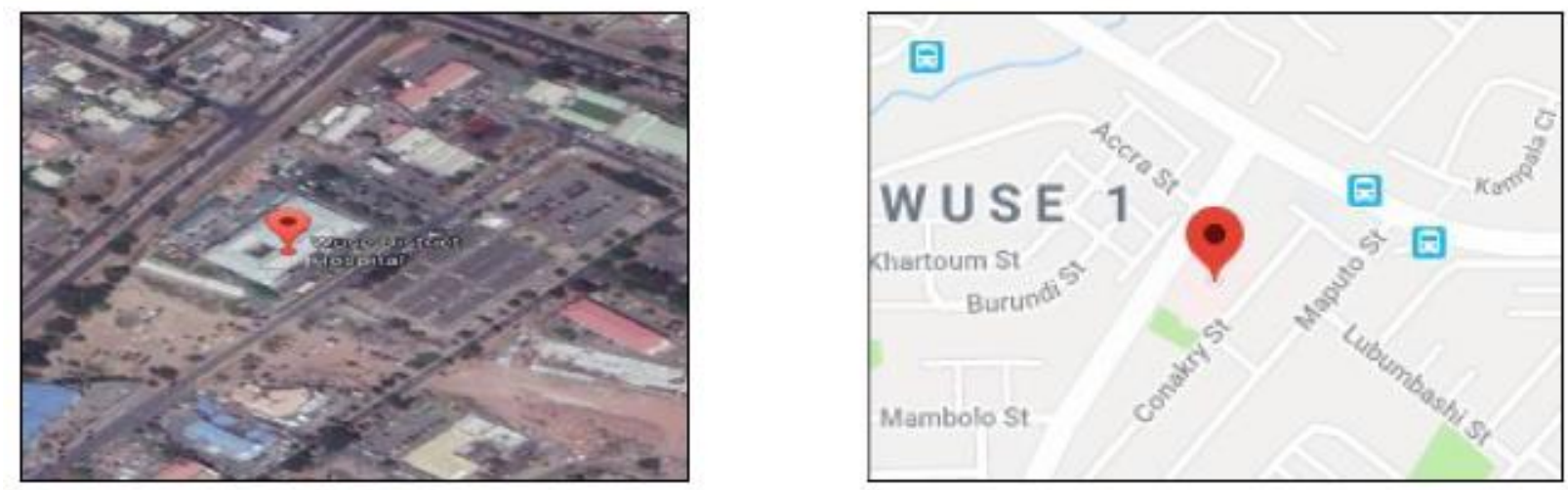

Figure1. Google map showing Wuse district hospital abuja nigeria

\section{Research design}

A retrospective study on the diagnosis and treatment of acute malaria based on hospital records of five years (2012-2016).

Sampling Technique: All the patients' records that were diagnosed of acute malaria confirmed by Giemsa stained thick and thin peripheral blood films prior to treatment at the General Out Patient and those on admission at FCT Abuja were considered.

Data collection: This included hospital records of patient diagnosed of acute malaria in the general outpatient and those on admission between 2012 and 2016 study years. These data were collated by the hospital medical record staff after two days training on data collection using the developed tools. 
DOI: $10.21522 /$ TIJPH.2013.06.02.Art017

ISSN: $2520-3134$

\section{Data analysis}

Data was entered and analyzed using IBM, SPSS Chicago version 25, Statistical software package. The Mean numbers of malaria patients were calculated by dividing total number of malaria patients enrolled in a particular year by 12 . Appropriate tables, graphs and percentages were displayed. A chi square test was performed to determine the level of significance using $95 \%$ confidence interval and $\mathrm{p}$ value.

\section{Ethical consideration}

Approval for the study was obtained from the FCT Health and Human Services Secretariat Ethical Committee. Confidentiality of data was also maintained.

\section{Results}

An overall total of 22,934 patients' records meeting up with the study criteria were obtained from the Wuse District Hospital spanning from 2012 to 2016. Findings from the records showed that the least number of patients diagnosed with malaria was noted for the year 2014 with the record of a total 3409 patients seen in the hospital (Table 1). The year with the highest number of diagnosed acute malaria patients seen in the study hospital was 2015 with a total of 5236 patients. The overall picture of the socio-economic status of the patients diagnosed with acute malaria in the study hospital between 2012 and 2016 study years is shown on Table 1 below.

Distribution of patients diagnosed with acute malaria in the hospital in the year 2013 showed the males to have the highest prevalence within the study period while the least male prevalence was recorded for 2015. Overall more of the males $(50.7 \%)$ than the females $(49.3 \%)$ were diagnosed with acute malaria within the study period (Table 1). 


\begin{tabular}{|c|c|c|c|c|c|c|c|}
\hline 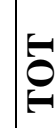 & $<\%$ & 尔 & 感 & 商 & $\begin{array}{l}\text { D. } \\
\text { in } \\
\text { in }\end{array}$ & 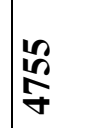 & đั. \\
\hline & 苞 & 於 & 尽 & & 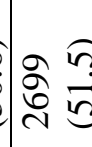 & 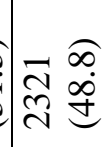 & $\begin{array}{l}\frac{n}{9} \\
\stackrel{9}{\exists}\end{array}$ \\
\hline מ. & $\sum \frac{0}{\pi} \widehat{d}$ & 吾完 & 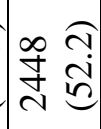 & & 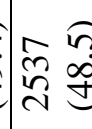 & 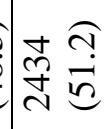 & 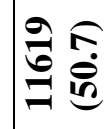 \\
\hline & 密 & 宇 & 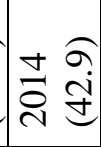 & & 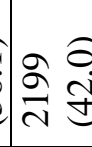 & 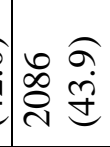 & 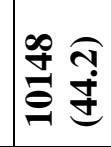 \\
\hline & $\widehat{\overparen{E}}$ & 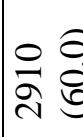 & 迈 & & 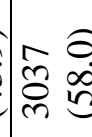 & 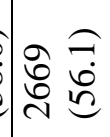 & 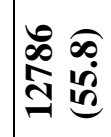 \\
\hline & 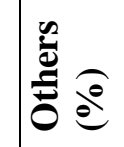 & $\begin{array}{l}n \\
0 \\
0 \\
0 \\
m\end{array}$ & 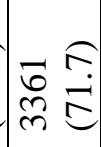 & & $\begin{cases}n & 0 \\
0 & \infty \\
0 & \infty\end{cases}$ & 崖 & 莡 \\
\hline & 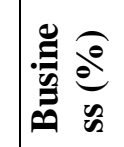 & 点 & 월 & & {$\left[\begin{array}{l}n \\
\infty \\
m \\
m\end{array}\right.$} & 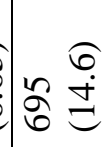 & 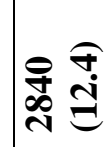 \\
\hline 気 & 20 & 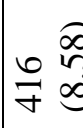 & 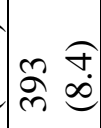 & & $\pm \widehat{m}$ & 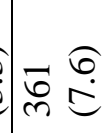 & r \\
\hline 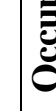 & $\int 0$ & 导字 & $\Xi \stackrel{6}{\sigma}$ & $\underset{\sim}{\mathbb{N}}$ & $\infty$ & 守 & $\Gamma_{\infty}^{\infty} \stackrel{\infty}{0}$ \\
\hline & 武 & 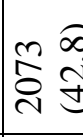 & 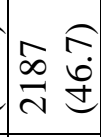 & 兽亲 & $\bar{m}$ & 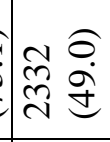 & 总胥 \\
\hline & $\hat{e}^{0}$ & 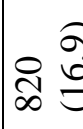 & $\overparen{\sigma} \stackrel{\widehat{\sigma}}{\stackrel{\theta}{=}}$ & $\underset{\underline{\infty}}{\stackrel{\infty}{+}}$ & 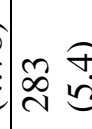 & $\vec{i} \underset{i}{\stackrel{d}{d}}$ & 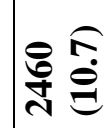 \\
\hline$\Xi$ & $=00$ & $\stackrel{m}{\tilde{E}}$ & $\underset{\infty}{\infty}$ & $\frac{\partial}{\sqrt{0}}$ & 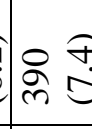 & 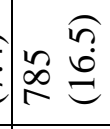 & 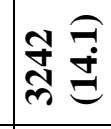 \\
\hline$\frac{5}{5}$ & $=\widehat{e}$ & $\bar{\infty} \underset{\infty}{\infty}$ & 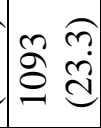 & 욜 & $\widehat{\widehat{\sigma}}$ & 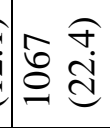 & 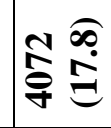 \\
\hline$\nu$ & & ลิ๋ & $\stackrel{m}{\stackrel{\sim}{~}}$ & 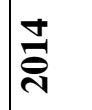 & $\stackrel{10}{\stackrel{\sim}{~}}$ & สั้ & _ \\
\hline
\end{tabular}


From the summary table 1 above, the Non Formal Educational accounted for $57.4 \%$ of the total number patients diagnosed with malaria followed by the patients with the basic primary education. Those with tertiary education accounted for the least number of patients diagnosed with acute malaria 2460 (10.7\%). Occupation-wise, the Public servants accounted for the least number 1487 ( 6.48\%) under the category of the educational status.

while Students, children and unemployed adults who belongs to the group of others accounted for $77.3 \%$ of the total number of patients. Those patients living in the rural accounted for $55.7 \%$ to those in urban settlements.

The findings from the 5 years retrospective study on the educational status of the patients diagnosed with acute malaria in Wuse District Hospital is shown on Table 2.

Table2. Educational status of patients diagnosed with acute malaria in Wuse district hospital

\begin{tabular}{|l|l|l|l|l|}
\hline Year & \multicolumn{4}{|l|}{ Education } \\
\hline & Primary & Secondary & Tertiary & NFE \\
\hline $\mathbf{2 0 1 2}$ & $881(18.2)$ & $1073(22.1)$ & $820(16.9)$ & $2073(42.8)$ \\
\hline $\mathbf{2 0 1 3}$ & $1093(23.3)$ & $784(16.7)$ & $623(13.3)$ & $2187(46.7)$ \\
\hline $\mathbf{2 0 1 4}$ & $399(11.7)$ & $210(6.2)$ & $163(4.8)$ & $2637(77.4)$ \\
\hline $\mathbf{2 0 1 5}$ & $632(12.1)$ & $390(7.4)$ & $283(5.4)$ & $3931(75.0)$ \\
\hline $\mathbf{2 0 1 6}$ & $1067(22.4)$ & $785(16.5)$ & $571(12.0)$ & $2332(49.0)$ \\
\hline Total & $\mathbf{4 0 7 2 ( 1 7 . 8 )}$ & $\mathbf{3 2 4 2 ( 1 4 . 1 )}$ & $\mathbf{2 4 6 0 ( 1 0 . 7 )}$ & $\mathbf{1 3 1 6 0 ( 5 7 . 4 )}$ \\
\hline
\end{tabular}

From the table 2 above, an overall total of 13,160 patients diagnosed within the study period with acute malaria did not have formal education, accounting for $57.4 \%$ of the total number of patients diagnosed with acute malaria. The patients who had up to Tertiary education accounted for the least $(10.7 \%)$ number of diagnosed malaria patients during the study period

Those with primary education accounted for $4072(17.8 \%)$ and was highest in $2013(23.3 \%)$ while those with secondary education accounted for 3242 (14.1\%) and was highest in 2012 (16.9\%)

In 2014, those patients with Non Formal Education were highest 2637 (77.4\%) compared to those with tertiary education which were lowest 163 (4.8\%)

The analysis of the mean for the educational status of the patients diagnosed with acute malaria in Wuse District Hospital within the study period is shown on Table 3.

Table 3. Mean number for the educational status of patients diagnosed with acute malaria in Wuse district hospital between 2012 and 2016

\begin{tabular}{|l|l|l|l|l|}
\hline Year & \multicolumn{4}{l}{ Education } \\
\hline & Primary & Secondary & Tertiary & NFE \\
\hline $\mathbf{2 0 1 2}$ & 73.4 & 89.4 & 68.3 & 172.8 \\
\hline $\mathbf{2 0 1 3}$ & 91.1 & 65.3 & 51.9 & 182.3 \\
\hline $\mathbf{2 0 1 4}$ & 33.3 & 17.5 & 13.6 & 219.8 \\
\hline $\mathbf{2 0 1 5}$ & 52.7 & 32.5 & 23.6 & 327.6 \\
\hline $\mathbf{2 0 1 6}$ & 88.9 & 65.4 & 47.6 & 194.3 \\
\hline
\end{tabular}

From the table, the mean number of malaria patients with Non Formal Education is highest (327.6) in 2015. Those with tertiary education has the lowest mean number of cases (13.6) in 2014

The mean number of patient with primary education is highest in 2013 (91.1) and lowest in 2014 (33.3) compared to the mean number of patient with secondary education was highest in 2012 (89.4) and lowest in 2014 (17.5).

The mean number of patients with tertiary education was highest in 2012 (68.3) 
Figure 2 below shows the analysis of the educational status of patients diagnosed with acute malaria in Wuse District Hospital Abuja. Those patients with no formal education were highest in 2015(3931) and lowest in 2012. Those patients with tertiary education were highest in 2012(820) and lowest in 2014(163).

Those with primary education were highest in 2013(1093) and lowest in 2014(399) while those with secondary education were highest in 2012(1073) and lowest in 2014(210).

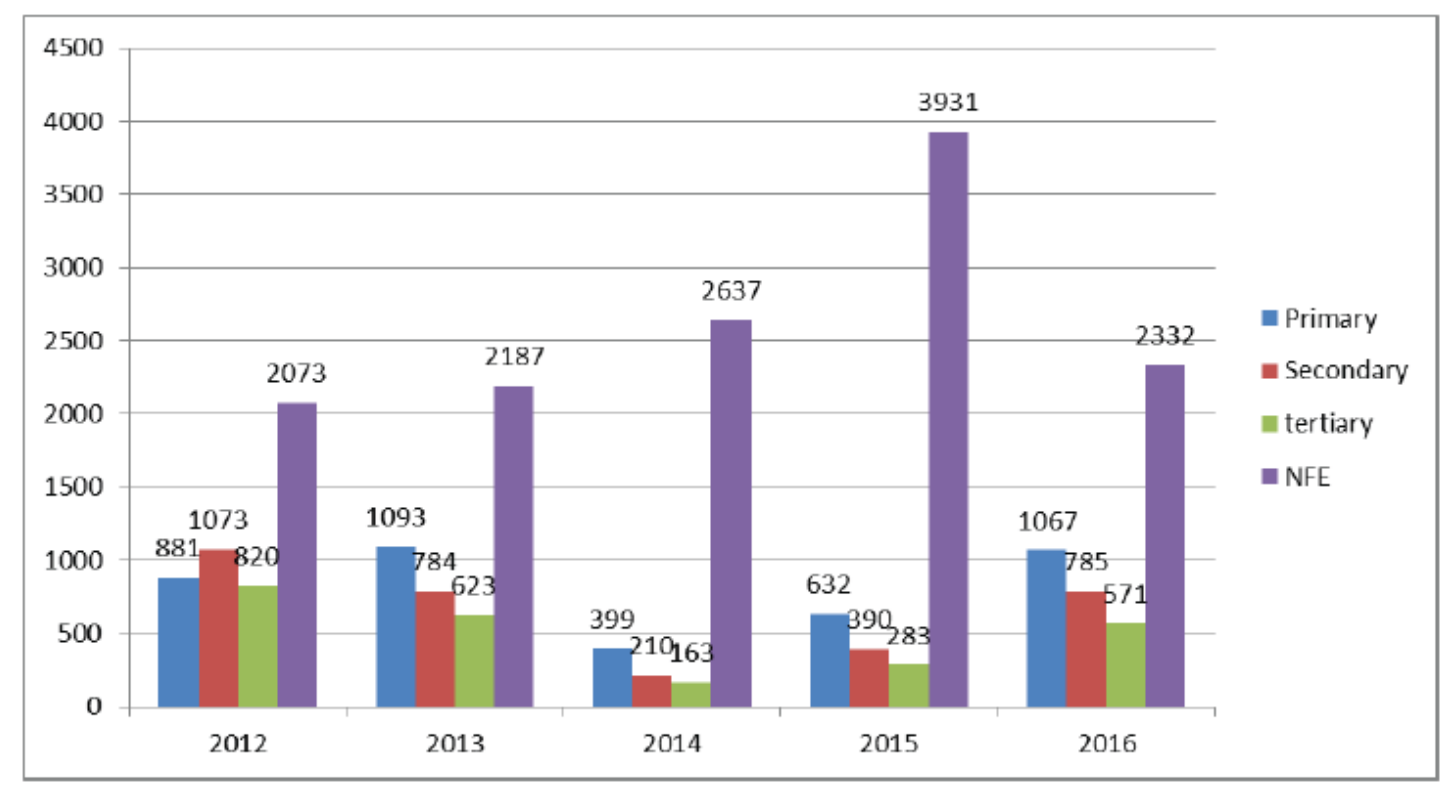

Figure2. Educational status of patients diagnosed with acute malaria in Wuse district Hospital between 2012 and 2016 study period

The chi-square statistic for Education is 180.6571 . The p-value is .00001 . The result is significant at $\mathrm{p}<.05$. Since the $\mathrm{p}$ value is less than the level of significance, we reject the null hypotheses and conclude there is relationship between educational status and malaria infection occurrence.

The correlation analysis shows that the value of $\mathrm{R}$ for primary variable is -0.5306 . This is a moderate negative correlation, the value of $\mathrm{R}$ for secondary variable is -0.6481 . This is a moderate negative correlation also. The value of $\mathrm{R}$ for tertiary variable is -0.6693 . This is a moderate negative correlation also. This means that the higher the level of education, the lower the occurrence of malaria infection and vice versa. In other words the education status plays a role in the occurrence of diagnosed acute malaria.

The result of the five year retrospective study on the occupational status of patients diagnosed with acute malaria in Wuse district hospital Abuja is shown on Table 4.

Table 4. Occupational status of patients diagnosed with acute malaria in Wuse District Hospital between 2012 and 2016 study period

\begin{tabular}{|l|l|l|l|l|}
\hline \multicolumn{5}{|l}{ Occupation } \\
\hline & CS & PS & Business & Others \\
\hline $\mathbf{2 0 1 2}$ & $240(5.0)$ & $416(8.6)$ & $726(15.0)$ & $3465(71.5)$ \\
\hline $\mathbf{2 0 1 3}$ & $171(3.6)$ & $393(8.4)$ & $762(16.3)$ & $3361(71.7)$ \\
\hline $\mathbf{2 0 1 4}$ & $224(6.6)$ & $143(4.2)$ & $309(9.1)$ & $2733(80.2)$ \\
\hline $\mathbf{2 0 1 5}$ & $89(1.7)$ & $174(3.3)$ & $348(6.6)$ & $4625(88.3)$ \\
\hline $\mathbf{2 0 1 6}$ & $147(3.1)$ & $361(7.6)$ & $695(14.6)$ & $3552(74.7)$ \\
\hline & $\mathbf{8 7 1}$ & $\mathbf{1 4 8 7}$ & $\mathbf{2 8 4 0}$ & $\mathbf{1 7 7 3 6}$ \\
\hline & & & & \\
\hline
\end{tabular}


From the table 4 above, the Civil Servants accounted for the lowest number of patients diagnosed with malaria within the study period while 'others' which included; unemployed youths / adults, children and students accounted for the highest number of patients diagnosed with acute malaria.

Those patients who were civil servants were the group of patients with the lowest rate of diagnosed acute malaria $(240 ; 5.0)$ in 2012 and overall least diagnosed in 2015 (89: 1.7). The patients who were captured as business persons recorded the second highest of diagnosed acute malaria cases throughout the study period. Likewise all the persons captured as 'others' which included unemployed youths / adults, children and students, maintained highest rate of diagnosed acute malaria cases throughout the study period with the highest rate of $88.3 \%$ in the year 2015 .

The analysis of the mean number for occupational status of patients diagnosed with acute malaria in Wuse district hospital Abuja in the five years retrospective study is shown on Table 5.

Table 5. Mean number for occupation status of patients diagnosed with acute malaria in Wuse district hospital between 2012 and 2016 study period

\begin{tabular}{|l|l|l|l|l|}
\hline \multicolumn{5}{|l|}{ Occupation } \\
\hline & CS & PS & Business & Others \\
\hline $\mathbf{2 0 1 2}$ & 20 & 34.7 & 60.5 & 288.8 \\
\hline $\mathbf{2 0 1 3}$ & 14.3 & 32.8 & 63.5 & 280.1 \\
\hline $\mathbf{2 0 1 4}$ & 18.7 & 11.9 & 25.8 & 227.8 \\
\hline $\mathbf{2 0 1 5}$ & 7.4 & 14.5 & 29.0 & 385.4 \\
\hline $\mathbf{2 0 1 6}$ & 12.3 & 30.1 & 57.9 & 296.0 \\
\hline & & & & \\
\hline
\end{tabular}

From the table 5 above, the Civil Servants have the lowest mean number of cases (7.4) in 2015 and other years except in 2014, while the group identified as 'others' had the highest mean number of cases through the years under study.

The mean number of cases for public servants were highest in 2012 (34.7) and lowest in 2014 (11.9) while the mean number of patient of those whose occupation is business were highest in 2013 (63.5) and lowest in 2014 (25.8). This is further illustrated on Figure 3.

Figure 3 below shows the analysis of the occupational status of patients diagnosed with acute malaria in Wuse District Hospital in the five years retrospective study. Those patients classified as 'others' were highest in 2015(4625) and lowest in 2014(2733). Those patients that were public servants were highest in 2013(393) and lowest in 2015(89). Those who were public servant were highest in 2012(416) and lowest in 2014(143). 


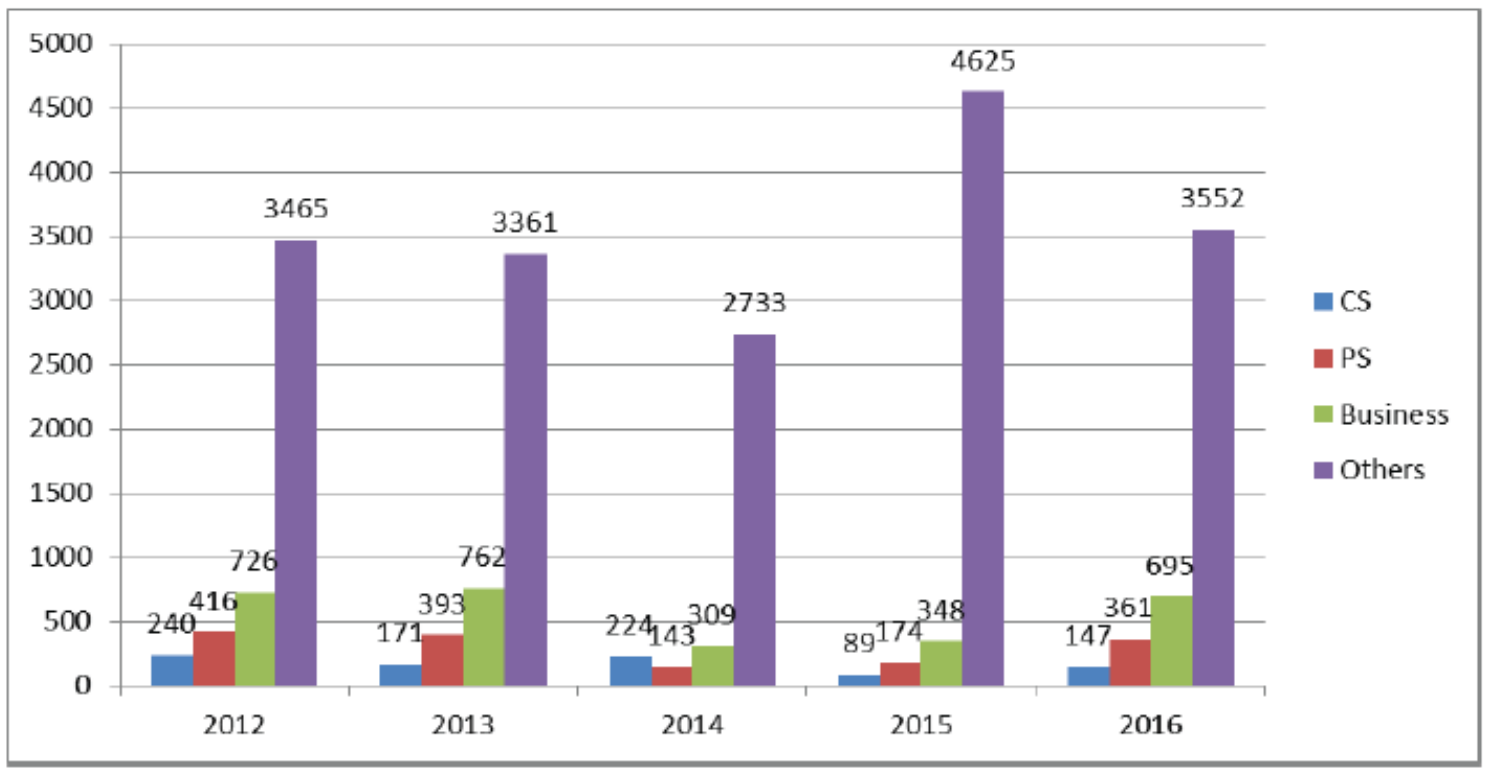

Figure 3. Occupational status of patients diagnosed with acute malaria in Wuse district hospital between 2012 and 2016 study period

The chi-square statistic for Occupation is 62.0118. The p-value is .00001. The result is significant at $\mathrm{p}<.05$.

Since the $\mathrm{p}$ value is less than the level of significance, we reject the null hypotheses and conclude there is a relationship between occupational status and malaria infection occurrence.

The correlation analysis shows the value of $\mathrm{R}$ is -0.8258 . This is a strong negative correlation, which means that, the high the occupational status, the lower the occurrence of malaria infection and vice versa

The geographical or residential location of the patients under study was grouped into 2: rural and urban settings. The analysis of the residential location of patients diagnosed with acute malaria within the study period is shown on Table 8. Those patients who resided in the rural area were highest in 2015 (3037: 58.0\%) and lowest in 2014 (1497: 43.9\%).

Those patients that resided in the Urban areas were highest in 2016 (2086: 43.9\%) and lowest in 2014 (1912: 56.1\%) Table 6

Table 6. Residential Locations of patients diagnosed with acute malaria in Wuse district hospital between 2012 and 2016 study years

\begin{tabular}{|l|l|l|}
\hline \multicolumn{2}{|l|}{ Location } \\
\hline & Rural & Urban \\
\hline $\mathbf{2 0 1 2}$ & $2910(60.0)$ & $1937(40.0)$ \\
\hline $\mathbf{2 0 1 3}$ & $2673(57.0)$ & $2014(43.0)$ \\
\hline $\mathbf{2 0 1 4}$ & $1497(43.9)$ & $1912(56.1)$ \\
\hline $\mathbf{2 0 1 5}$ & $3037(58.0)$ & $2199(42.0)$ \\
\hline $\mathbf{2 0 1 6}$ & $2669(56.1)$ & $2086(43.9)$ \\
\hline & $\mathbf{1 2 7 8 6}$ & $\mathbf{1 0 1 4 8}$ \\
\hline
\end{tabular}

From the table, those patients living in the rural areas accounted for the highest number of patients diagnosed with acute malaria compared with the patients living in the urban areas. In 2014 however, it was observed that more of the patients diagnosed for acute malaria during this period were from the urban areas (1912: 56.1\%) compared to those in the rural areas (1497: 43.9\%). 
DOI: $10.21522 /$ TIJPH.2013.06.02.Art017

ISSN: $2520-3134$

The analysis of the mean number for Location for the study patients diagnosed with acute malaria in Wuse District Hospital Abuja Nigeria within the 2012 -2016 study period is shown on Table 7 and further illustrated on Figure 4.

Table 7. Mean number for Location of patients diagnosed with acute malaria in wuse district hospital within 2012 -2016 study years

\begin{tabular}{|l|l|l|}
\hline \multicolumn{3}{|l|}{ Location } \\
\hline Years & Rural & Urban \\
\hline $\mathbf{2 0 1 2}$ & 242.5 & 161.4 \\
\hline $\mathbf{2 0 1 3}$ & 222.8 & 167.8 \\
\hline $\mathbf{2 0 1 4}$ & 124.8 & 159.3 \\
\hline $\mathbf{2 0 1 5}$ & 253.1 & 183.3 \\
\hline $\mathbf{2 0 1 6}$ & 222.4 & 173.8 \\
\hline
\end{tabular}

From the table 7 above, the mean number for residential location of patients diagnosed with acute malaria showed clearly that the patients that resided in the rural areas over the years had more cases of malaria through the years except in 2014 when the reverse was the case. The highest mean numbers of cases were seen in 2015 with the lowest in 2016. The mean number of cases for urban location was lowest (159.3) in 2014 and highest in 2015(183.3)

Figure 4 below shows the distribution of patients diagnosed with acute malaria in Wuse District Hospital. The number of cases were highest in 2015 (3037) and lowest in 2014 (1497) for those who reside in the rural area. The number of cases were highest in 2015 (2199) and lowest in 2014 (1912) for those residing in the urban areas.

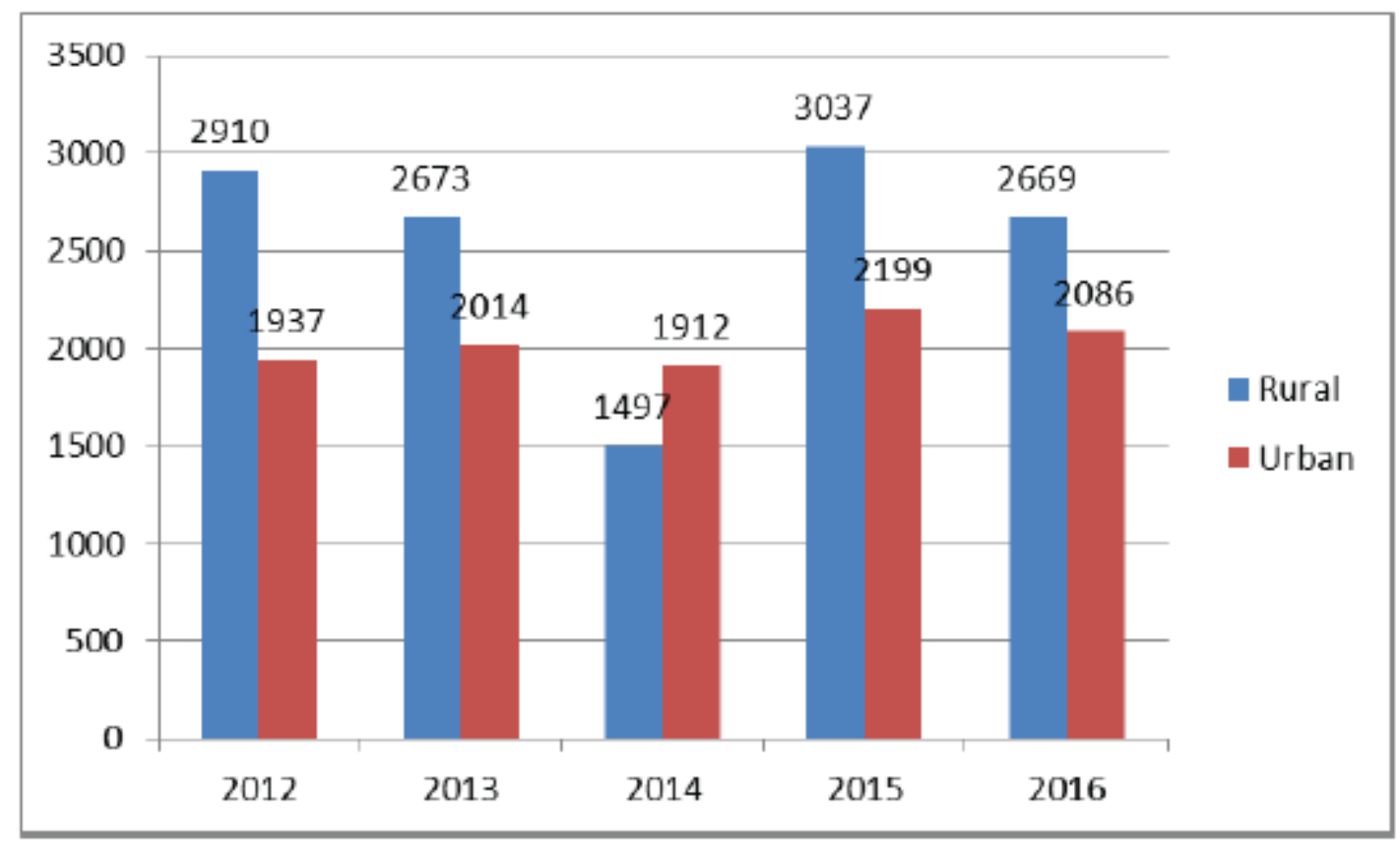

Figure 4. Urban rural distribution of patients diagnosed with acute malaria in wuse district hospital between 2012 and 2016

The chi-square statistic is 20.2199 . The p-value is .000452 . The result is significant at $p<.05$

Since the $\mathrm{p}$ value is less than the level of significance, we reject the null hypotheses and conclude there is a relationship between patients' residential location in the Rural or Urban to malaria infection occurrence. 


\section{Discussion}

This is a five year retrospective study to access Socio-Economic inequalities in the occurrence of diagnosed acute malaria based on hospital records at FCT Abuja. An association between educational status and the occurrence of malaria infection shows that, the lower the educational status, the higher the occurrence of malaria infection. Education plays a role on areas of awareness about malaria prevention and control. Asanterabi Lowassa et al (2012) also observed that education level of the household heads had a significant association with malaria treatment seeking behavior. Incontrast to Kavita Yadav et al (2014) on socioeconomic determinants for malaria transmission observed no significant association between education level and malaria occurrence.

A statistical relationship between the occupational status of the patients and malaria occurrence means that, the lower the occupational status, the higher the occurrence of malaria infection. Furthermore, those who are not employed visited the hospital frequently which has correlation with poverty. This was in line with Ruby Naz et al (2016) who worked on Pattern of Malaria Infection at Tertiary Care Hospital of Haryana- India A Hospital Based Study and found association between educational and occupational status to malaria infection

\section{Conclusion}

The level of educational status, occupational status and residence of patients plays significant roles in the prevention and control of malaria infection.

In view of the above, there is the need to:

i. Imbibe the culture of good health seeking behaviour which is an important strategy to reduce the burden of malaria. This will involve sensitization activities and awareness campaign to the FCT rural populace on the prevention and control of malaria infection. The use of radio and Television jingles in local languages will go a long way in improving knowledge on malaria.

ii. Creation of community empowerment and poverty alleviation programmes so as to improve the income level of house-holds in the rural areas. The above study revealed that, occupational status and residing in the rural area was related to the occurrence of malaria infection.

\section{Contribution to knowledge}

Unlike other retrospective studies on malaria, this current study dwell on the Socio Economic indices of the patients. The study gave details on the educational status, occupational status and urban or rural residential area of the patients.

\section{Acknowledgement}

The authors are grateful to the management and medical records staff of Wuse District Hospital for using their facility for the study. We also acknowledge the staff and faculty members of the Texila America School of Public Health for their support.

\section{References}

[1]. Abate et al.; licensee BioMed Central Ltd. 2013, Community knowledge, attitude and practice about malaria in a low endemic setting of Shewa Robit Town, northeastern Ethiopia. BMC Public Health BMC series open, inclusive and trusted201313:312 DOI: 10.1186/1471-2458-13-312.

[2]. Ahmad Yahaya Maigemu 2015. Influence of Religion on Malaria Control Practices among Household Heads in Zamfara State North West Nigeria Journal of Culture, Society and Development www.iiste.org ISSN 24228400 An International Peer-reviewed Journal Vol.10.

[3]. Asanterabi Lowassa et al 2013 Social economic factors and malaria transmission in Lower Moshi, Northern Tanzania.

[4]. Eve Worrall et al, January 2003, the relationship between socio-economic status and malaria: a review of the literature.

[5]. Federal Capital Territory (FCT) Abuja, Health and Human Health Services Secretariat (HHSS) 2015 Statistical bulletin.

[6]. Federal Capital Territory (FCT) 2009 Baseline survey report.

[7]. Federal Ministry of Health (FMOH) 2014b Malaria Control Report 2015. 
DOI: $10.21522 /$ TIJPH.2013.06.02.Art017

ISSN: $2520-3134$

[8]. Federal Ministry of Health (FMOH) National Malaria Control Programme 2014.

[9]. Humanitarian manual on malarial control 2010, Published in 2010, pages 10 to 15.

[10]. Karunamoorthi K, Bekele M. 2012. Changes in Malaria Indices in an Ethiopian Health Centre: A Five Year Retrospective Analysis. Health Scope 1(3): 118-26. DOI: 10.5812/jhs.7076.

[11]. Merit Mora-Ruiz, et al 2014, Socio economic factors, attitudes and practices associated with malaria prevention in the coastal plain of Chiapas, Mexico. Malaria Journal201413:157.

[12]. National Bureau of Statistics (NBS), National Malaria Indicator Survey (NMIS), 2015.

[13]. National Demographic and Health Survey report 2013.

[14]. Ruby Naz et al 2016. Pattern of Malaria Infection at Tertiary Care Hospital of Haryana-A Hospital Based Study International Journal of Current Microbiology and Applied Sciences ISSN: 2319-7706 Volume 5 Number 2(2016) pp. 330-337 Journal homepage: http://www.ijcmas.com.

[15]. Salwa Dawaki et al 2015. Is Nigeria winning the battle against malaria? Prevalence, risk factors and KAP assessment among Hausa communities in Kano State.

[16]. Snow et al 2013 on Estimating Malaria Burden in Nigeria: A Geostatistical Modelling Approach. License (open-access, http://creativecommons.org/licenses/by-nc/3.0/).

[17]. Vincent Were et al 2018 on socioeconomic health inequality in malaria indicators in rural western Kenya: evidence from a household malaria survey on burden and care-seeking behavior Malaria Journal 17:16https://doi.org/10.1186/s12936-018-2319-0.

[18]. W.P. O'Meara et al 2009. The impact of primary health care on malaria morbidity - defining access by disease burden Tropical Medicine International Health Journal.

[19]. World Health Organization (WHO) Global malaria report 2014.

[20]. World Health Organization (WHO) Global malaria report 2017 ISBN 978-92-4-156552www.who.int/malaria.

[21]. World Health Organization (WHO) World Malaria Report 2012 www.who.int/malaria.

[22]. World Health Organization (WHO) Global Malaria Programme 2015 website at http://www.who.int/ malaria/mpac/mpac-sept2015-erg-mip-report.pdf.

[23]. Yadav et al.; licensee BioMed Central Ltd. 2014. Socio-economic determinants for malaria transmission risk in an endemic primary health centre in Assam, India. 10.1186/2049-9957-3-19. 